\title{
Epiglottic diffuse B-cell malignant lymphoma: A case report
}

\author{
HUNG-MIN CHANG ${ }^{1}$, CHIUNG-CHON LI $^{1}$, STELLA CHIN-SHAW TSAI $^{1,2}$ and TANG-YI TSAO ${ }^{3}$ \\ Departments of ${ }^{1}$ Otolaryngology, ${ }^{2}$ Medical Research and ${ }^{3}$ Pathology, \\ Tungs' Taichung Metro Harbor Hospital, Taichung 43503, Taiwan, R.O.C.
}

Received July 6, 2015; Accepted July 23, 2015

DOI: $10.3892 / \operatorname{mco} .2015 .675$

\begin{abstract}
A 55-year-old male patient was admitted to our department with complaints of dysphagia and throat soreness for 2 months. A tumor of the left epiglottis, with an irregular surface, was identified by video laryngoscopy. The diagnosis of malignant lymphoma was confirmed by biopsy during laryngomicrosurgery. The atypical diffuse lymphocytic lymphoma was positive for $\mathrm{CD} 20$ and $\mathrm{Bcl}-2$, and negative for CD3, CD10 and Bcl-1. The diagnosis was diffuse large B-cell malignant lymphoma. The patient was treated with eight cycles of rituximab with cyclophosphamide + doxorubicin + vincristine + prednisolone (R-CHOP regimen). This is a rare case of extranodal non-Hodgkin lymphoma occurring in the epiglottis.
\end{abstract}

\section{Introduction}

Lymphomas constitute a group of blood cell tumors that develop from lymphatic cells (1). There are numerous subtypes of lymphomas (2), with the two main categories being Hodgkin's lymphoma (HL) and non-Hodgkin lymphomas (NHLs) (3). Approximately 90\% of lymphomas are NHLs, with diffuse large B-cell lymphoma (DLBCL) being the most common type (3).

DLBCL occurs primarily in older individuals, with a median age at diagnosis of $\sim 70$ years (4), although it may also occur in children and young adults in rare cases (5). DLBCL is an aggressive tumor, which may arise in virtually any part of the body (6). Extranodal NHL occurring primarily in the epiglottis is extremely rare, accounting for merely $0.7 \%$ of all NHLs and $1 \%$ of malignant laryngeal tumors (7). We herein present a rare case of DLBCL involving the epiglottis.

Correspondence to: Dr Hung-Min Chang, Department of Otolaryngology, Tungs' Taichung Metro Harbor Hospital, 699 Taiwan Boulevard, Section 8, Wuchi, Taichung 43503, Taiwan, R.O.C. E-mail: misosilo@gmail.com

Key words: diffuse large B-cell malignant lymphoma, non-Hodgkin lymphoma, extranodal non-Hodgkin lymphoma, epiglottis, laryngeal lymphoma

\section{Case report}

A 55-year-old previously healthy man presented with complaints of dysphagia and throat soreness for 2 months. The patient did not have a history of fever, night sweats, body weight loss or fatigue. On examination of the neck, no palpable mass was detected and the overlying skin was not erythematous or warm to the touch. On intraoral examination, there were no specific findings. Video laryngoscopy revealed a left epiglottic tumor with an irregular surface (Fig. 1). The hematological tests were normal, apart from increased erythrocyte sedimentation rate. Blood smear examination revealed no evidence of blast cells. The renal and liver function tests were normal and the patient was HIV-negative.

The diagnosis of malignant lymphoma was confirmed by biopsy during laryngomicrosurgery. The specimens exhibited lymphoid tissue with monotonous lymphoid cells, with nearly complete destruction of lymphoid architecture and the proliferation of medium- to large-sized atypical lymphocytes (compared with histiocytes), characterized by moderate irregular nuclear shape, coarse chromatin, numerous small distinct nucleoli and prominent large nucleoli, moderate amount of light eosinophilic cytoplasm and frequent mitoses. The atypical large lymphocytes were diffusely positive for CD20 and $\mathrm{Bcl}-2$, and negative for CD3, CD10 and Bcl-1, indicating the diagnosis of malignant DLBCL (Fig. 2).

Tumor staging was performed. Magnetic resonance imaging revealed an irregular infiltrative tumor sized $4 \times 2.6 \times 2.5 \mathrm{~cm}$ in the left hypopharyngeal wall, involving the left side of the epiglottis and the left piriform sinus. Positron emission tomography-computed tomography revealed multiple focal areas of increased fluorodeoxyglucose uptake involving the left hypopharynx and bilateral neck lymph nodes, without distant metastasis. Bone marrow biopsy was negative for tumor involvement (stage II disease). The patient was scheduled to receive eight cycles over 4-6 weeks with rituximab $375 \mathrm{mg} / \mathrm{m}^{2}$ and cyclophophamide $750 \mathrm{mg} / \mathrm{m}^{2}+$ doxorubicin $50 \mathrm{mg} / \mathrm{m}^{2}$ + vincristine $1.4 \mathrm{mg} / \mathrm{m}^{2}+$ prednisone $100 \mathrm{mg}$ daily ( $\mathrm{R}-\mathrm{CHOP}$ regimen). To date, the patient has received three cycles and is followed up in our department.

\section{Discussion}

The symptoms of lymphoma may include enlarged lymph nodes, fever, cold sweats, weight loss, pruritus and fatigue $(8,9)$. However, our patient did not present with any of those symptoms. 


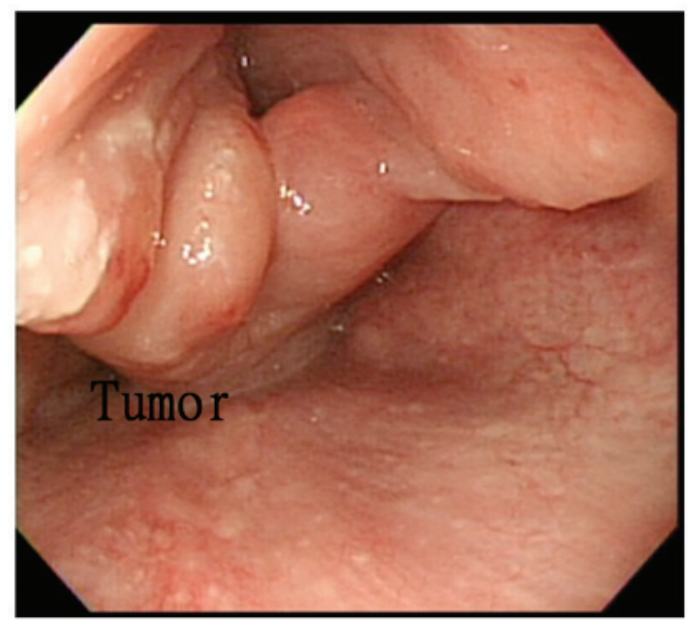

Figure 1. Left epiglottic tumor with irregular surface.
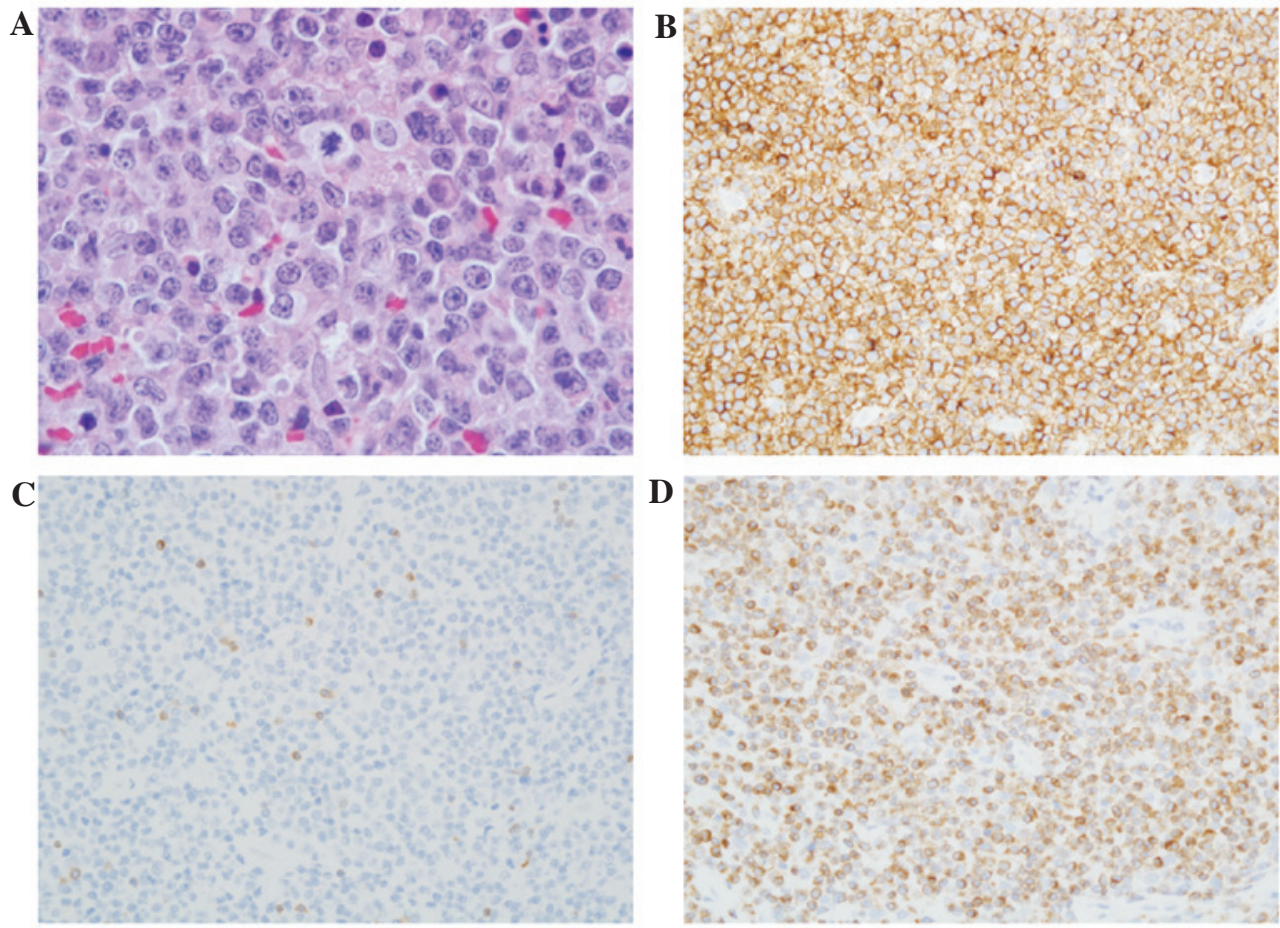

Figure 2. The atypical large lymphocytes were diffusely positive for CD20 and Bcl-2, and negative for CD3, CD10 and Bcl-1, indicating the diagnosis of diffuse large B-cell malignant lymphoma. (A) Tumor cells (hematoxylin and eosin stain; magnification, x1,000). Immunohistochemical staining for (B) CD20 (magnification, x400); (C) CD3 (magnification, x400); and (D) Bcl-2 (magnification, x400).

There are numerous subtypes of lymphoma, the main two being HL and NHL (2). NHLs constitute a heterogeneous group of malignancies characterized by abnormal clonal proliferation of T cells, B cells, or both. Approximately 90\% of lymphomas are NHLs (3). The risk factors for common types of NHL include autoimmune diseases, HIV/AIDS, infection with human T-lymphotropic virus, consuming large amounts of meat and fat, immunosuppressive medications and certain pesticides (9). The diagnosis is usually confirmed by lymph node biopsy. Blood, urine and bone marrow tests may also be useful for diagnosis. Imaging may then be performed to determine whether the cancer has spread and to which location. Spread most commonly occurs to the lungs, liver and/or brain (9). The head and neck is the second most common region for extranodal lymphoma, the first being the gastrointestinal tract (10). Extranodal NHLs occurring primarily in the epiglottis are extremely rare, accounting for merely $0.7 \%$ of all NHLs and $1 \%$ of malignant laryngeal tumors (7). Supraglottic cancer is almost exclusively squamous cell carcinoma. Therefore, our case of DLBCL in the left epiglottis is very rare. The treatment of lymphoma may combine chemotherapy, radiation therapy, targeted therapy, surgery and other methods (8). R-CHOP is the most common chemotherapeutic regimen for NHL and our patient was scheduled to receive eight cycles over 4-6 weeks. In the United States, the overall 5-year survival rate of HL is $~ 85 \%$ (11) and 
of NHL $69 \%$ (12). According to the international prognostic index established for patients aged $<60$ years, the outcome of patients with extranodal DLBCL is similar to that of patients with nodal DLBCL (13).

In conclusion, we presented a case of rare primary extranodal NHL of the epiglottis. The patient is currently under treatment with the R-CHOP regimen, and has received three cycles of chemotherapy to date.

\section{References}

1. Taylor EJ (ed): Dorland's Illustrated Medical Dictionary. 29th edition. Saunders, Philadelphia, p1038, 2000.

2. Bardia A (ed): Johns Hopkins Patients' Guide to Lymphoma Jones and Bartlett Learning, Burlington, Massachusetts, p6, 2010

3. Leukemia and Lymphoma Society: The Lymphoma Guide Information for Patients and Caregivers. https://www.lls $\mathrm{org} / \mathrm{sites} / \mathrm{default} /$ files/file_assets/lymphomaguide.pdf. Accessed June 20, 2014.

4. Smith A, Howell D, Patmore R, Jack A and Roman E: Incidence of haematological malignancy by sub-type: A report from the Haematological Malignancy Research Network. Br J Cancer 105: $1684-1692,2011$.

5. Smith A, Roman E, Howell D, Jones R, Patmore R and Jack A; Haematological Malignancy Research Network: The Haematological Malignancy Research Network (HMRN): A new information strategy for population based epidemiology and health service research. Br J Haematol 148: 739-753, 2010.
6. Kumar V, Abbas AK, Fausto N and Aster J (eds): Robbins and Cotran Pathologic Basis of Disease. 8th edition. Elsevier Saunders, Philadelphia, p607, 2010.

7. King AD, Yuen EH, Lei KI, Ahuja AT and Van Hasselt A: Non-Hodgkin lymphoma of the larynx: CT and MR imaging findings. AJNR Am J Neuroradiol 25: 12-15, 2004.

8. National Cancer Institute. General Information About Adult Hodgkin Lymphoma. http://www.cancer.gov/types/lymphoma/ patient/adult-hodgkin-treatment-pdq\#section/all. Accessed June 20, 2014.

9. National Cancer Institute. General Information About Adult Non-Hodgkin Lymphoma. http://www.cancer.gov/types/ lymphoma/patient/adult-nhl-treatment-pdq\#section/all. Accessed June 20, 2014.

10. Jacobs C, Weiss L and Hoppe RT: The management of extranodal head and neck lymphomas. Arch Otolaryngol Head Neck Surg 112: 654-658, 1986.

11. National Cancer Institute. SEER Stat Fact Sheets-Hodgkin Lymphoma. http://seer.cancer.gov/statfacts/html/hodg.html. Accessed August 26, 2012.

12. National Cancer Institute. SEER Stat Fact Sheets: Non-Hodgkin Lymphoma. http://seer.cancer.gov/statfacts/html/nhl.html. Accessed June 18, 2014.

13. Essadi I, Ismaili N, Tazi E, Elmajjaoui S, Saidi A, Ichou M and Errihani H: Primary lymphoma of the head and neck: Two case reports and review of the literature. Cases J 1: 426, 2008. 